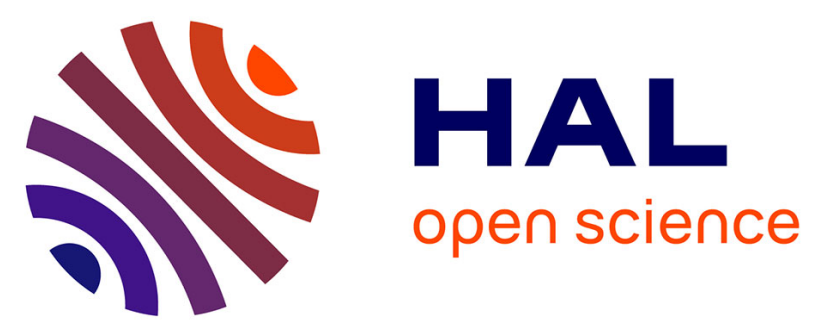

\title{
The role of the non-neuronal cholinergic system in inflammation and degradation processes in osteoarthritis
}

Alice Courties, Ariane Do, Sarah Leite, Manon Legris, Laure Sudre, Audrey

Pigenet, Juliette Petit, Geoffroy Nourissat, Adeline Cambon-Binder, Uwe

Maskos, et al.

\section{To cite this version:}

Alice Courties, Ariane Do, Sarah Leite, Manon Legris, Laure Sudre, et al.. The role of the nonneuronal cholinergic system in inflammation and degradation processes in osteoarthritis. Arthritis \& rheumatology, 2020, 10.1002/art.41429 . pasteur-02935940

\section{HAL Id: pasteur-02935940 \\ https://hal-pasteur.archives-ouvertes.fr/pasteur-02935940}

Submitted on 10 Sep 2020

HAL is a multi-disciplinary open access archive for the deposit and dissemination of scientific research documents, whether they are published or not. The documents may come from teaching and research institutions in France or abroad, or from public or private research centers.
L'archive ouverte pluridisciplinaire HAL, est destinée au dépôt et à la diffusion de documents scientifiques de niveau recherche, publiés ou non, émanant des établissements d'enseignement et de recherche français ou étrangers, des laboratoires publics ou privés.

$$
\text { Copyright }
$$


DR. ALICE COURTIES (Orcid ID : 0000-0001-8122-701X)

Article type : Full Length

The role of the non-neuronal cholinergic system in inflammation and degradation processes in osteoarthritis

\section{Running Head : Non-neuronal cholinergic system involvement in osteoarthritis}

Alice Courties, MD, $\mathrm{PhD}^{1,2,3,4}$, Ariane Do, $\mathrm{MD}^{1,2,3,4}$, Sarah Leite ${ }^{1,2,3,4}$, Manon Legris ${ }^{1,2,3,4}$, Laure Sudre, $\mathrm{PhD}^{1,2,3,4}$, Audrey Pigenet ${ }^{1,2,3,4}$, Juliette Petit, $\mathrm{MD}^{1,2,3,4}$, Geoffroy Nourissat, $\mathrm{MD}, \mathrm{PhD}^{2,5}$, Adeline Cambon-Binder, $\mathrm{MD}^{1,2,6}$, Uwe Maskos, $\mathrm{PhD}^{7}$, Francis Berenbaum, $\mathrm{MD}, \mathrm{PhD}^{1,2,3,4}$, Jérémie Sellam, $\mathrm{MD}, \mathrm{PhD}^{1,2,3,4}$.

1. Sorbonne Université, Paris, France.

2. INSERM UMRS_938, CRSA, Paris, France

3. Inflammation-Immunopathology-Biotherapy Department (DHU i2B), Paris, France

4. Department of Rheumatology, Assistance Publique - Hôpitaux de Paris (AP-HP), Saint-Antoine Hospital, Paris, France

5. Department of Orthopedic Surgery, Clinique Maussins, Groupe Ramsay générale de santé, 67 rue de Romainville, 75019, Paris

6. Department of Orthopedic Surgery, AP-HP, Saint-Antoine Hospital, Paris, France

7. Institut Pasteur, Neurobiologie intégrative des systèmes cholinergiques, CNRS UMR 3571, Département de Neuroscience, Paris, France

\section{Corresponding author:}

Prof. Francis BERENBAUM

Hôpital Saint-Antoine,

Service de rhumatologie

184, rue du Faubourg Saint-Antoine

This article has been accepted for publication and undergone full peer review but has not been through the copyediting, typesetting, pagination and proofreading process, which may lead to differences between this version and the Version of Record. Please cite this article as doi: 10.1002/ART.41429

This article is protected by copyright. All rights reserved 
75012 Paris, FRANCE

Tel: + 33149282520

Fax : + 33149282513

francis.berenbaum@aphp.fr

Word count: 3709

Funding: This work was supported by the French Society of Rheumatology (SFR) and the Assistance Publique - Hôpitaux de Paris (AP-HP). Laure Sudre was funded by the network Research of Osteoarthritis Diseases (ROAD).

Competing interests: None.

\section{Abstract (250 words)}

Objectives: The non-neuronal cholinergic system represents non-neuronal cells that have the biochemical machinery to synthetize de novo and/or respond to acetylcholine (ACh). We investigated this biochemical machinery in chondrocytes and its involvement in osteoarthritis (OA).

Methods: Expression of the biochemical machinery for ACh metabolism and nicotinic ACh receptors (nAChR), particularly $\alpha 7 \mathrm{nAChR}$, in human $\mathrm{OA}$ and murine chondrocytes was determined by PCR and ligand-binding. We investigated the mRNA expression of the human duplicate $\alpha 7 \mathrm{nACh}$ subunit, called CHRFAM7A, which is responsible for a truncated $\alpha 7 \mathrm{nAChR}$. We assessed the effect of nAChR on chondrocytes activated by IL1 $\beta$ and the involvement of $\alpha 7 \mathrm{nAChR}$ using chondrocytes from wild-type (WT) and $\alpha 7$-deficient Chrna7-/-mice. The role of $\alpha 7 \mathrm{nAChR}$ in OA was explored after medial meniscectomy (MNX) in WT and Chrna7-/-mice.

Results: Human and murine chondrocytes express the biochemical partners of the non-neuronal cholinergic system $(n=5)$ and a functional $\alpha 7 \mathrm{nAChR}$ at their cell surface. The expression of CHRFAM7A in human OA chondrocytes correlated positively with MMP3 $(r=0.38, p<0.05)$ and MMP13 $(r=0.48, p<0.05)$ expression $(n=23)$. Nicotine decreased the IL1 $\beta$-induced IL6 and MMPs expression in a dose-dependent manner in WT but not in Chrna $7^{-/-}$chondrocytes. MNX Chrna7-/mice displayed more severe OA cartilage damage (OARSI score of $4.46 \pm 1.09, \mathrm{n}=7$ ) than MNX WT mice $(3.05 \pm 0.9, \mathrm{n}=9, \mathrm{p}<0.05)$. 
Conclusion: The non-neuronal cholinergic system is functionally expressed in chondrocytes. Stimulation of nAChR induces anti-inflammatory and anti-catabolic activity through $\alpha 7 \mathrm{nAChR}$, but the anti-catabolic activity may be mitigated by truncated $\alpha 7 \mathrm{nAChR}$ in human chondrocytes. In vivo experiments strongly suggest that $\alpha 7 \mathrm{nAChR}$ has a protective role in $\mathrm{OA}$.

\section{INTRODUCTION}

While osteoarthritis (OA) is the most common musculoskeletal disease, available treatments still only treat symptoms and are either not highly effective or associated with safety issues. Therefore, it remains an unmet need to develop new therapeutic targets based on a better understanding of OA pathophysiology.

The interplay between the nervous system and inflammation has been mainly described during infection or acute inflammation (1). Along this line, the autonomic nervous system, particularly the parasympathetic system, has shown immunomodulatory and anti-inflammatory properties after stimulation of the vagus nerve (2). The parasympathetic system is composed of cholinergic neurons that release acetylcholine $(\mathrm{ACh})$ as the chemical mediator of neurotransmission. However, ACh is not only a neurotransmitter, as it can be synthesized by non-neuronal cells such as $\mathrm{T}$ cells or resident cells (e.g., keratinocytes) (3). These cells can also express the biochemical machinery responsible for the transport and degradation of synthesized ACh and nicotinic and/or muscarinic ACh receptors. This ACh production and responsive system (i.e., ACh receptors) define the non-neuronal cholinergic system.

Anti-inflammatory properties of non-neuronal ACh produced by $\mathrm{T}$ cells have been demonstrated in sepsis, viral infections and rheumatoid arthritis involving activation of the alpha 7 nicotinic ACh receptor $(\alpha 7 \mathrm{nAChR})$ expressed by splenic macrophages $(2,4,5)$. The $\alpha 7 \mathrm{nAChR}$ is composed of five $\alpha 7$ subunits (Chrna7). The $\alpha 7 \mathrm{nAChR}$ mediates its biological effect through ionic flux, especially intracellular calcium entrance. However, it has been suggested that ACh could activate direct metabotropic signalling, such as JAK2-STAT3 or MAP-kinase signalling (6). Recently in humans, genetic rearrangement between a duplicate of the 5-10 exons of Chrna7 and a copy of the FAM7A gene led to a specific human duplicate responsible for the production of a truncated protein (CHRFAM7A) (7). This truncated protein may decrease the biological response to ACh and thus promote inflammation $(8,9)$. 
During OA, chondrocytes are activated under different stresses (mechanical, inflammatory, metabolic) and are then responsible for the production of inflammatory and catabolic mediators that induce cartilage degradation. Two recent publications showed that systemic nicotinic ACh receptor activation by intraperitoneal injection of nicotine may limit OA lesions in a monoiodoacetate murine model of OA $(10,11)$. Using a chemical antagonist compound (i.e., methyllycaconitine), they suggested that $\alpha 7 \mathrm{nAChR}$ was involved in macrophage and chondrocyte activation. However, these results were not confirmed in another study (12).

Likewise, the role of nicotinic ACh receptors in OA remains controversial. Furthermore, it is unknown whether articular chondrocytes display the non-cholinergic system to produce ACh and express nicotinic ACh receptors or whether activation of cholinergic receptors influences the chondrocytic production of cytokines and metalloproteases. The objective of this study was to determine the expression and role of the non-neuronal cholinergic system on chondrocyte activation and OA, especially through the involvement of $\alpha 7 \mathrm{nAChR}$.

\section{MATERIALS AND METHODS}

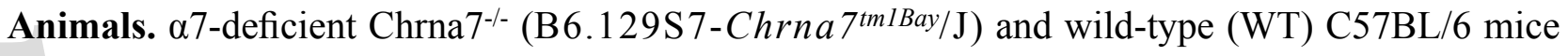
were used for in vitro and in vivo experiments (13). Animals were fed ad libitum. The animal facility was granted approval (C-75-12-01) by the French Administration. All experiments were conducted according to the European Communities Council Directive (2010/63/UE) for the care and use of animals for experimental procedures and complied with the regulations of the French Ethics Committee in Animal Experiment « Charles Darwin » registered at the «Comité National de Réflexion Ethique sur l'Experimentation Animale » (Ile-de-France, Paris, no5). All procedures were approved by this committee (no \#9173-20170330618083277).

Induction of experimental OA. Meniscectomy (MNX) was performed on 10-12-week-old male Chrna $7^{-/-}$and WT mice as previously described $(14,15)$. Briefly, MNX was performed by a trained surgeon : after cutaneous incision, the medial meniscotibial ligament was sectioned and medial meniscus extrusion and sectioning was performed on the right knee. Mice were euthanized 8 weeks after MNX for analyzes. Sham procedure was performed on the right knee of independent male WT and Chrna $7^{-/-}$mice through the same approach but without any ligament transection or meniscectomy.

Histological analysis. After sacrifice, the right knee joints were removed and fixed for 24 hours in $4 \%$ paraformaldehyde-phosphate-buffered saline (PBS) (PFA) solution at $4{ }^{\circ} \mathrm{C}$. Knee joints were 
then decalcified in $500 \mathrm{mM}$ EDTA for 4 weeks, and all tissues were embedded in paraffin. Sagittal sections of $5 \mu \mathrm{m}$ were obtained. Knee tissue sections were stained with Safranin O/fast green for OARSI histologic OA scoring at the tibial and femoral condyles (16). For each knee, the final score is the mean score of tibial and femoral condyles obtained from 3 slides separated by $50 \mu \mathrm{M}$ by two readers blinded to the genotype. Synovitis scores obtained were the sum of the score of the synovial hyperplasia (0-3) and of sub-synovial inflammation (0-3) as previously published (17). Osteophytes scoring was performed as previously published on a 0-3 scale (14).

Alpha-bungarotoxin staining. Human and WT murine chondrocytes were grown on slides for 5 days and incubated with biotinylated-bungarotoxin (Thermo Fisher Scientific, Waltham, Massachusetts, USA) in the cell culture medium at $4^{\circ} \mathrm{C}$ overnight at $5 \mu \mathrm{g} / \mathrm{L}$ and $20 \mu \mathrm{g} / \mathrm{L}$, respectively. Cells were washed three times with PBS and then fixed for $15 \mathrm{~min}$ at room temperature in $4 \%$ PFA. Slides were then incubated at room temperature in streptavidinhorseradish peroxidase (HRP) (Vectastain ${ }^{\circledR}$-Vector Laboratories, Inc. CA, USA) solution using DAB (Vector Laboratories, Inc. CA, USA) substrate and counterstained with haematoxylin. Semiquantitative scoring was performed on four different zones of $0.1 \mathrm{~mm}^{2}$ of the slides, and the stained cells were reported relative to the total number of cells.

Primary culture of murine articular chondrocytes. Murine chondrocytes were obtained from the femoral head and the knee articular cartilage of 5- to 6-day-old Chrna $7^{-/-}$and WT mice, as previously described (18). Briefly, after matrix digestion, chondrocytes were seeded at $8 \times 10^{3}$ cells per $\mathrm{cm}^{2}$ and expanded for a week in Dulbecco's modified Eagle's medium (DMEM) with $1 \mathrm{~g} / \mathrm{L}$ glucose supplemented with $100 \mathrm{U} / \mathrm{mL}$ penicillin (P), $100 \mathrm{mg} / \mathrm{mL}$ streptomycin (S), $4 \mathrm{mM}$ glutamine (Glu) and 10\% foetal calf serum (FCS). Each littermate was used for one experiment. Cells were fasted for 24 hours before treatment in serum-free media DMEM P/S/Glu containing $0.1 \%$ bovine serum albumin (BSA).

Treatment of primary cultures of murine chondrocytes. Chrna $7^{-/-}$and WT chondrocytes were stimulated for $24 \mathrm{~h}$ with IL-1 $(10 \mathrm{ng} / \mathrm{mL})$ (PeproTech, Rocky Hill, NJ, USA) with or without pretreatment for 15 minutes with nicotine (Sigma, Saint-Louis, USA) at 1, 10 or $100 \mu \mathrm{M}$. After $24 \mathrm{~h}$, cell lysates were collected for mRNA isolation, and media were collected for protein assessment by enzyme-linked immunosorbent assay (ELISA). 
Human OA chondrocyte experiments. Human OA chondrocytes were isolated from the cartilage of patients undergoing joint arthroplasty for OA at Saint-Antoine Hospital or at the Clinique des Maussins-Ramsay (Paris, France), as previously described (19). Informed consent for the use of tissue was obtained from each patient before surgery. Experiments using human samples were approved by a French Institutional Review Board (Comité de Protection des Personnes, Paris Ile de France 5 and Commission Nationale de l'Informatique et des Libertés). Briefly, cartilage was dissected in small pieces, rinsed in saline buffer and digested with collagenases I and II (Roche, Penzberg, Germany). Chondrocytes were then seeded in plates at $20 \times 10^{3}$ cells per $\mathrm{cm}^{2}$ and expanded in DMEM with $4.5 \mathrm{~g} / \mathrm{L}$ glucose $\mathrm{P} / \mathrm{S} / \mathrm{Glu}$ containing $10 \% \mathrm{FCS}$. At confluence, chondrocytes were starved for 24 hours in DMEM with $4.5 \mathrm{~g} / \mathrm{L}$ glucose $\mathrm{P} / \mathrm{S} / \mathrm{Glu}$ with $0.1 \% \mathrm{BSA}$ and then stimulated for $24 \mathrm{~h}$ with IL-1 $\beta(10 \mathrm{ng} / \mathrm{mL})$ (PeproTech, Rocky Hill, NJ, USA) with or without pretreatment with a specific $\alpha 7$ nicotinic receptor agonist, PNU-282987 (Abcam, Cambridge, U.K.), at $100 \mu \mathrm{M}$ (20). After 24 h, cell lysates were collected for mRNA analysis.

Calcium assay. Primary cultures of murine chondrocytes in 96-well plates were starved after 1 week of culture. Measurements were performed using a Fluo-4 NW calcium assay kit (Molecular Probes, Eugene, USA) following the manufacturer's instructions. Briefly, after being rinsed with saline phosphate buffer (PBS), the cells were incubated with probenecid in the kit buffer to block cationic organic transporters for 30 minutes at $37^{\circ}$ and then 30 minutes at room temperature. Then the live analysis until 3.8 minutes was performed using an inverted fluorescence an inverted microscope (Olympus IX83 inverted), immediately after the addition of an agonist: ionomycin at $10 \mu \mathrm{M}$ (positive control) or nicotine at $10 \mu \mathrm{M}$. The fluorescence was then quantified by Image J.

RNA extraction and RT-PCR. Total RNA was extracted from chondrocytes using an RNeasy kit (Qiagen, Hilden, Germany), and concentrations were determined using a Nanodrop (DeNovix DS11). Reverse transcription involved 500 ng total RNA with an Omniscript RT kit (Qiagen, Hilden, Germany). mRNA levels of interleukin 6 (IL6), metalloproteases (MMP)-3, MMP9, MMP13, nicotinic ACh receptor subunits ( $\alpha 1-7,9$ and $\beta$ 1-4) and the human duplicate CHRFAM7A were quantified using a Light Cycler LC480 (Roche Diagnostics) by qRT-PCR. Levels of mRNA were normalized to those of murine hypoxanthine guanine phosphoribosyltransferase (HPRT) and to human $18 \mathrm{~S}$. The relative quantitative value is equal to $2^{-\Delta \mathrm{CT}}$ where $\Delta \mathrm{CT}$ is equal to (CT target- CT HPRT or $18 \mathrm{~S}$ ). For nAchR expression, we therefore normalized on a calibrator (a mix of mRNA samples).

This article is protected by copyright. All rights reserved 
RT-PCR was performed to determine the expression of factors in the cholinergic system, i.e., carnityl acetyltransferase (carAT), choline acetyltransferase (ChAT), vesicular acetylcholine transporter (VAChT), acetylcholine esterase (AChE), butyrylcholine esterase (BChE) and choline transporter-1 (CHT1), in human and murine chondrocytes. For RT-PCR, PCR was performed with a final volume of $20 \mu \mathrm{L}$ containing $10 \mu \mathrm{L}$ of Taq polymerase (Qiagen), $0.25 \mu \mathrm{M}$ of each forward and reverse primer (Supplementary S1 table 1 for murine and table 2 for human primers) and $6 \mu \mathrm{L}$ of cDNA. For each primer, we determined the best melting temperature and applied a negative control (water) and a positive control (murine and human cDNA from the spinal cord). Amplification was performed for 40 cycles. For electrophoretic separation, RT-PCR products were subjected to $2 \%$ TRIS-acetate-EDTA agarose gel electrophoresis.

ELISA. The protein concentrations of IL6 and MMP3 released in the supernatant by WT and Chrna $7^{-/-}$chondrocytes after IL1 $\beta$ with or without nicotine were measured using a Quantikine ELISA kit (R\&D Systems, Lille, France).

Statistical analysis. A non-parametric Wilcoxon test and a Mann-Whitney test were used for matched paired and unpaired data, respectively. A P-value $<0.05$ indicated statistical significance. Data are expressed as the mean \pm standard error of the mean (SEM). Statistical analyzes were performed using GraphPad Prism 5 (GraphPad Software, San Diego, CA, USA).

\section{RESULTS}

\section{Murine and human OA chondrocytes express the non-neuronal cholinergic system}

Human OA and WT murine chondrocytes expressed carAT, VAChT, AChE (mRNA) in 5 independent experiments using 5 different samples. All murine chondrocytes expressed CHT1 while none of the human chondrocytes expressed it. Four murine chondrocytes and two human chondrocytes expressed BChE, and none of them expressed ChAT. The mRNA expression of each molecular actor of the non-neuronal cholinergic system was positive for cDNA in the spinal cord (i.e., positive control) and negative in water, confirming the specificity of the primers (Figure 1A). 
Activation of nAChR exerts anti-inflammatory and anti-catabolic action on murine and human chondrocytes

We focused on the role of nicotine, which binds all the so-called nicotinic receptors, on chondrocyte activation. We incubated murine WT chondrocytes with nicotine stimulated by IL1 $\beta$. Nicotine decreased the mRNA expression of IL6 in a dose-dependent manner between 1 and 10 $\mu \mathrm{M}$ by $37.3 \pm 8 \% ; 70.8 \pm 6 \%$ and $46.8 \pm 10 \%$ for 1,10 and $100 \mu \mathrm{M}$ nicotine, respectively $(\mathrm{n}=5$, $\mathrm{p}<0.05$ ) (Figure 1B). Additionally, nicotine decreased the mRNA expression of MMP3 in a dosedependent manner between 1 and $10 \mu \mathrm{M}$ (by $46.5 \pm 8 \%$; $68.3 \pm 10 \%$ and $67.8 \pm 11 \%$ for 1,10 and $100 \mu \mathrm{M}$ nicotine, respectively, $\mathrm{p}<0.05$ ) (Figure 1B) and of MMP13 and MMP9 mRNA (Supplementary S2). The anti-inflammatory and anti-catabolic effects reached a plateau between the 10 and the $100 \mu \mathrm{M}$ dose. These results were confirmed at the protein level since nicotine decreased the levels of IL1 $\beta$-induced IL6 in a dose-dependent manner according to ELISA with decreases of $38.9 \pm 16.9 \%$ (not significant), $65.6 \pm 4 \%$, and $67.7 \pm 6.4 \%$ for 1,10 and $100 \mu \mathrm{M}$ nicotine, respectively $(n=5 ; p<0.05)$ (Figure 1C). Nicotine also decreased the levels of MMP3 secreted by murine chondrocytes after IL $1 \beta$ stimulation, with a decrease of $54 \pm 11 \%$ for $100 \mu \mathrm{M}$ nicotine $(n=5 ; p<0.05)$ (Figure 1C).

Murine and human chondrocytes express several nicotinic receptor subunits, especially the functional $\alpha 7 \mathrm{nAchR}$

Since we identified anti-inflammatory and anti-catabolic effects of nicotine on chondrocytes, we questioned which nAchR subunits are expressed by human and murine chondrocytes. Using qPCR, we found that murine chondrocytes expressed $\alpha 4, \alpha 5, \alpha 6, \alpha 7$ and $\beta 4$ subunits (between 31 and 33 cycles), while human OA chondrocytes expressed $\alpha 5, \alpha 6, \alpha 7$ and $\beta 2, \beta 4$ subunits (between 30 and 35 cycles) (Figure 2A). As both chondrocytes expressed the Chrna7 subunit, we determined whether murine and human chondrocytes express the functional homopentameric receptor $\alpha 7 \mathrm{nAchR}$ using $\alpha$-bungarotoxin, a specific antagonist of functional $\alpha 7 \mathrm{nAChR}$. Murine and human chondrocytes bound $\alpha$-bungarotoxin in two independent experiments each (Figure 2B and 2C). Using semi-quantitative scoring, we found that $27.8 \pm 4.8 \%$ of murine chondrocytes and $36.3 \pm 4.5 \%$ of human OA chondrocytes expressed a functional homopentamer $\alpha 7 \mathrm{nAchR}$ (Figure $2 B$ and 2C).

This article is protected by copyright. All rights reserved 


\section{Human chondrocytes express both native Chrna7 and duplicate CHRFAM7A, and CHRFAM7A expression positively correlates with MMP3 and -13 expression}

To better decipher $\alpha 7 \mathrm{nAChR}$ expression in human cells, we evaluated the expression of both native Chrna7 and the human-specific duplicate CHRFAM7A subunit in human OA chondrocytes. The structural differences between native Chrna7 and duplicate CHRFAM7A are explained in Figure 3A. We evaluated the expression of both forms in human OA chondrocytes from 23 patients with knee OA undergoing arthroplasty (69\% women, mean \pm standard deviation $69.6 \pm 7.9$ years old). Human OA chondrocytes expressed both the duplicate CHRFAM7A and the native Chrna7 subunits, but the mRNA expression of CHRFAM7A was significantly higher than that of native Chrna7 ( $\mathrm{p}=0.046$ ) (Figure 3B). Interestingly, basal human OA chondrocyte CHRFAM7A mRNA expression correlated with MMP3 $(\mathrm{r}=0.38, \mathrm{n}=23, \mathrm{p}<0.05)$ and MMP13 $(\mathrm{r}=0.48, \mathrm{n}=23$, $\mathrm{p}<0.05$ ) mRNA expression (Figure 3C). High-level expression of CHRFAM7A was thus associated with a more pronounced catabolic profile since the expression of MMP3 and MMP13 was significantly higher in chondrocytes expressing high levels of CHRFAM7A (defined by CHRFAM7A $\geq$ median which was 1.4) compared with those who expressed low levels of CHRMAF7A (CHRFAM7A $<$ median) (Figure 3D).

The $\alpha 7 n A C h R$ pathway is critical for anti-inflammatory and anti-catabolic activity induced by cholinergic system activation

We hypothesized that the anti-inflammatory effect of nAChR activation was due to $\alpha 7 \mathrm{nAChR}$. Therefore, we investigated the effect of nicotine on IL1 $\beta$-stimulated Chrna $7^{-/-}$chondrocytes. In contrast to the result in WT chondrocytes, nicotine had no protective effect and thus did not decrease IL6 and MMP3 mRNA expression at any dose in Chrna $7^{-/-}$chondrocytes (Figure 4A). This phenomenon was confirmed at the protein level (Figure 4B). Therefore, the antiinflammatory and anti-catabolic effects of nicotine depend on $\alpha 7 \mathrm{nAchR}$. We excluded any compensation effect of other subunits in the Chrna $7^{-/-}$chondrocytes because the expression level of the subunits of nAChR ( $\alpha 1-7,9$ and $\beta 1-4)$ did not differ between WT and Chrna $7^{-/-}$chondrocytes (not shown). To determine if the effect of nicotine was calcium-dependent, we performed calcium entrance experiments in WT and $\mathrm{Chrna} 7^{-/-}$murine chondrocytes and found no intracellular entrance of calcium in either type of chondrocyte, meaning that activation of $\alpha 7 \mathrm{nAchR}$ involves other pathways (Figure 4C-E). To confirm the anti-inflammatory and anti-catabolic effects of the $\alpha 7 \mathrm{nAChR}$ pathway in human chondrocytes, we tested the effect of a specific $\alpha 7 \mathrm{nAChR}$ agonist, 
PNU-282987 $(100 \mu \mathrm{M})$, on IL1 $\beta$-stimulated chondrocytes: PNU-282987 decreased the mRNA expression levels of IL6 (-23.1 $\pm 5.9 \%)$, MMP3 (-16.5 $\pm 6.5 \%)$, and MMP13 (-39.4 $\pm 4.1 \%)$ induced by IL1 $\beta$ alone (Figure 4F).

\section{Impairment of the $\mathrm{ACh} / \mathrm{Chrna} 7$ axis by deletion of Chrna7 aggravates cartilage degradation} in murine OA

Finally, we determined the involvement of $\alpha 7 \mathrm{nAChR}$ in vivo using the MNX model of OA in WT and Chrna7 ${ }^{-/-}$mice. We did not find any macroscopic phenotypic or behavioural differences between WT and Chrna7-/- mice before sacrifice. The weight was similar between the groups (27.4 $\pm 0.7 \mathrm{~g}$ for WT sham mice, $\mathrm{n}=7 ; 28.3 \pm 0.5$ for Chrna $7^{-/-}$sham mice, $\mathrm{n}=5 ; 29.2 \pm 0.6 \mathrm{~g}$ for WT MNX mice, $\mathrm{n}=9$ and $28.3 \pm 0.8 \mathrm{~g}$ for Chrna7 ${ }^{-/-}$MNX mice, $\mathrm{n}=7$; not significant) (Figure 5B). MNX induces significant lesions of OA in both WT and Chrna7-/- mice compared to sham knees with more cartilage lesions, more osteophyte and more synovitis $(\mathrm{p}<0.05)$ (Figure $5 \mathrm{~A}$ and $\mathbf{5 C}$ ). In the sham experiments, there were no difference in the OARSI score between WT and Chrna7 ${ }^{-/-}$ $\left(0.42 \pm 0.1\right.$ for WT sham mice versus $0.84 \pm 0.51$ for Chrna $7^{-/-}$sham mice, $\left.\mathrm{p}=0.11\right)$ as well as in the osteophyte and synovitis scores (Figure 5D and 5E).

Eight weeks after MNX, Chrna7-/- mice display more severe OA cartilage damage than WT mice as assessed by the OARSI score (3.05 \pm 0.9 for WT MNX versus $4.46 \pm 1.09$ for Chrna7-/- MNX on a 0-6 score, 6 being the worst, $\mathrm{p}<0.05$ ) (Figure 5A and 5C). However, we did not find any difference in synovitis and osteophytes scores between WT and Chrna $7^{-/-}$mice after MNX (Figure 5D and 5E).

\section{DISCUSSION}

Our understanding of the role of the non-neuronal cholinergic system as a critical regulator of inflammation and immunity is growing but remains controversial and poorly investigated in OA pathophysiology $(21,22)$. Here, we showed that human and murine chondrocytes are part of the non-neuronal cholinergic system allowing local auto/paracrine action of ACh on joint cells. Stimulation of the functionally expressed homopentamer $\alpha 7 \mathrm{nAChR}$ decreased the inflammatory and catabolic activation of human and murine chondrocytes induced by IL1 $\beta$. Furthermore, $\alpha 7 \mathrm{nAChR}$ has a protective role in OA since the lack of $\alpha 7 \mathrm{nAChR}$ was associated with more severe cartilage degradation in the murine MNX model. 
The role of the non-neuronal cholinergic system has been previously investigated in other cell types. Likewise, non-neuronal production of ACh by T-cells is essential to control viral infections (4). Additionally, the stimulation of ACh synthesis by T-cells could counteract the chronic and systemic inflammation in rheumatoid arthritis and in sepsis . However, very little is known about the non-neuronal cholinergic system in joint tissues, especially in cartilage. The synovial membrane expresses ChAT, the main enzyme responsible for the production of ACh and carAT, another enzyme for ACh synthesis (26). In addition, the synovium expresses $\mathrm{AChE}$ and $\mathrm{BChE}$, which are responsible for the degradation of ACh and several nicotinic ACh receptors, such as $\alpha 2-$ 7 and 9 subunits (but not $\beta$ nicotinic subunits) and muscarinic receptors M1, M3-M5 (26-28). Murine osteoblasts also express the entire spectrum of biochemical enzymatic machinery and most nicotinic receptors (29). Here, we showed for the first time that human OA and murine chondrocytes express the entire cholinergic system relevant for ACh synthesis (carAT), transport (VAChT), and degradation (AChE). Chondrocytes express carAT and no ChAT which is concordant with previous study that found carAT is the main enzyme responsible for ACh synthesis in non-neuronal cells (30). We found that choline transporter-1 (CHT1) is expressed by murine but not by human OA chondrocytes. However, Beckmann et al. established that other choline transporters were expressed in cartilage (choline transporter-like CTL-1 to 5, the organic cation transporter (OCT) 1 and 3 and the OCT novel-3) (28). These transporters allow choline recapture by the cells after $\mathrm{ACh}$ degradation which may constitute a rate-limiting step for ACh synthesis.

ACh acts on both muscarinic and nicotinic receptors, which are widely expressed by non-neuronal cells, making the cholinergic system complex. Since nicotinic receptors are also involved in inflammation and tissue remodelling in non-neuronal cells, we investigated their expression in chondrocytes. Nicotinic receptors are composed of 5 alpha and/or beta subunits, which comprise a heterogeneous family of hetero- or homopentamers. Chondrocytes express several alpha and beta nicotinic subunits, and most are preserved between mice and humans. Indeed, WT murine chondrocytes express $\alpha 4, \alpha 5, \alpha 6, \alpha 7$, and $\beta 4$ subunits, and human OA chondrocytes express $\alpha 5$, $\alpha 6, \alpha 7, \beta 2$, and $\beta 4$ subunits. Based on previously published data on other cell types, different combinations of nAChR pentamers can be expressed by chondrocytes (31). But importantly, 
human and murine chondrocytes both express the $\alpha 7 \mathrm{nAChR}$ homopentamer, as confirmed by $\alpha$ bungarotoxin binding, which is widely used for this purpose (32).

Our study demonstrated a regulatory effect of $\alpha 7 \mathrm{nAChR}$ in chondrocyte activation induced by IL1 $\beta$. In vitro, activation of nicotinic receptors by nicotine limits the induction of inflammatory and catabolic factors by IL $1 \beta$. Our results are in accordance with those reported by Liu et al., who showed that nicotine applied to IL1 $\beta$-stimulated rat chondrocytes inhibited signalling pathways,

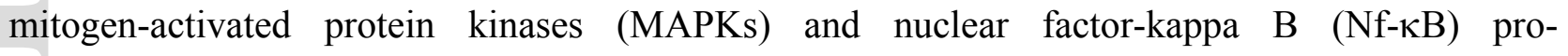
inflammatory pathways. However, they did not investigate the downstream effect of nicotinic receptor activation on cytokines and MMPs or which nicotinic receptors are involved in these processes. Here, we demonstrated that the anti-inflammatory and anti-catabolic effects of nicotine are due to $\alpha 7 \mathrm{nAChR}$ activation since nicotine did not counteract IL1 $\beta$ stimulation in Chrna7-/chondrocytes. In contrast to Liu et al., we used Chrna $7^{-/-}$cells, which are more robust and more specific than chemical antagonist compounds such as methyllycaconitine (MLA), an $\alpha 7 \mathrm{nAChR}$ antagonist. We did not find any action of nicotine on the entry of calcium, contrary to what has been previously published on human growth plate chondrocytes (33). The state of differentiation could explain this discrepancy. Despite calcium entry, $\alpha 7 \mathrm{nAChR}$ could have a direct metabotropic effect by a direct interaction with some substrates of signalling pathways ( $\mathrm{Nf}-\kappa \mathrm{B}$ and MAPKs), as previously reported in chondrocytes $(11,34)$. Finally, we did not use Ach in vitro because of its short half-life and of its lack of specificity since Ach activates both nicotinic and muscarinic also the muscarinic receptors that might be expressed by chondrocytes.

We confirmed the anti-inflammatory and anti-catabolic effect of $\alpha 7 \mathrm{nAChR}$ on human OA chondrocytes using a widely used and published specific $\alpha 7 \mathrm{nAChR}$ agonist, PNU-282987 (20,35). This result corroborates a previous study that showed the promotion of collagen synthesis by nicotine in human normal chondrocytes (36). However, the inflammatory and catabolic responses of human chondrocytes may depend on the expression level of the duplicate CHRFAM7A. We found that the expression level of the human-specific duplicate CHRFAM7A, which is responsible for a truncated protein of the $\alpha 7$ subunit, is associated with an enhanced catabolic profile (i.e., increased MMP expression). This duplicate contains exons 5-10 of the native gene of the alpha 7 subunit Chrna7, which transcribed most of the protein structure. However, the ligand binding site of this truncated protein is missing, leading to a decreased response to specific ligands, such as ACh or nicotine (37). The local expression of CHRFAM7A is suspected to be associated with 
some disease and inflammatory states, as demonstrated by the colon expression of CHRFAM7A in inflammatory bowel diseases (38). Interestingly, meta-analysis of observational studies have reported that smoking could be associated with less incident OA (39). Our study could give a rationale to these data. However, nicotine is just one of the compounds present in tobacco smoke and so the role of the other ones cannot be ruled out. Altogether, we still consider that even if nicotine could have some beneficial effects on cartilage, the multiple risks related to smoking far outweighs the conditional beneficial effect of nicotine.

Finally, we confirmed the involvement of $\alpha 7 \mathrm{nAChR}$ in OA in vivo. We observed that Chrna $7^{-/-}$ mice displayed more severe cartilage lesions than WT mice after MNX induction. This result confirms that mice lacking Chrna7 are associated with increased chondrocyte activation and cartilage degradation compared with WT mice and that $\alpha 7 \mathrm{nAChR}$ has a protective role in OA. This is the first study evaluating OA in Chrna $7^{-/-}$mice. These mice do not have behavioural and phenotypical difference compared to WT (40). However, we did not evaluate pain assessment. Liu et al. and Teng et al. previously reported that systemic administration of nicotine reduced monoiodoacetate (MIA) OA lesions $(10,11)$. They suggested that this effect was due to activation $\alpha 7 \mathrm{nAchR}$ since the protective effect of nicotine disappears after injection of methyllycaconitine (MLA), an $\alpha 7 \mathrm{nAChR}$ antagonist; however, the specificity of this chemical compound is questionable, and the administration of the combination of nicotine and MLA is somewhat artificial and potentially toxic to rats. In contrast to the more severe OA lesions caused by nicotine and MLA treatment in the MIA model, the exacerbated OA lesions in Chrna $7^{-/-}$MNX mice could be due to a loss of effect of endogen ACh on $\alpha 7 \mathrm{nAChR}$ in Chrna $7^{-/-}$chondrocytes. A weakness of this study is that since we used a model of full invalidation of Chrna7 gene and not a cartilage specific one, we cannot definitely conclude whether cartilage genetic deletion is the only factor involved in the exacerbated OA lesions in Chrna $7^{-/-}$mice. Of note, it is possible that deletion of Chrna7 in bone also contributes to the observed MNX phenotype.

Our study has several strengths. First, we confirmed $\alpha 7 \mathrm{nAChR}$ expression using various robust methods (i.e, $\alpha$-bungarotoxin). Antibody-based techniques for the assessment of $\alpha 7 \mathrm{nAChR}$ protein expression was not possible because of the unavailability of accurate and specific antibodies raised against the nicotinic subunit (41). We also evaluated for the first time the local expression of the specific human duplicate. Second, we used a mechanical model, which is much more representative of human OA than the highly inflammatory MIA model, far from human 
disease. Third, we used genetically modified mice instead of applying a combination of chemical compounds to mimic $\alpha 7 \mathrm{nAChR}$ inhibition.

In conclusion, human and murine chondrocytes belong to the non-neuronal cholinergic system. The alpha7 nicotinic ACh receptor is a crucial receptor able to limit the inflammatory and catabolic response of chondrocytes, and lacking this receptor can aggravate OA cartilage damage. In human chondrocytes, expression of the gene duplicate CHRFAM7A is associated with a more marked catabolic profile, while its role in OA remains to be investigated. Thus, the non-neuronal $\mathrm{ACh} / \alpha 7 \mathrm{nAChR}$ axis is involved in the pathophysiology of OA and could be a therapeutic target.

Acknowledgements: The authors acknowledge Professor Alain Sautet (MD) and Doctor Francois-Paul Ehkirch (MD) for providing human knee joints, Pradeep Sacitharan (PhD) and Professor Pierre Aucouturier (MD, PhD) for their advice and helpful discussions, Kristell Wanderhick for her help in histological staining, Pierre Galichon and Dominique Prié for their advices on the calcium assay, and Tatiana Ledent for providing the animal facilities.

\section{References}

1. Tracey KJ. Neurons Are the Inflammatory Problem. Cell 2018;173:1066-1068.

2. Borovikova LV, Ivanova S, Zhang M, Yang H, Botchkina GI, Watkins LR, et al. Vagus nerve stimulation attenuates the systemic inflammatory response to endotoxin. Nature 2000;405:458462.

3. Wessler I, Kirkpatrick CJ. Acetylcholine beyond neurons: the non-neuronal cholinergic system in humans. Br J Pharmacol 2008;154:1558-1571.

4. Cox MA, Duncan GS, Lin GHY, Steinberg BE, Yu LX, Brenner D, et al. Choline acetyltransferase-expressing $\mathrm{T}$ cells are required to control chronic viral infection. Science 2019;363:639-644.

5. Wang H, Yu M, Ochani M, Amella CA, Tanovic M, Susarla S, et al. Nicotinic acetylcholine receptor alpha7 subunit is an essential regulator of inflammation. Nature 2003;421:384-388.

6. Marrero MB, Bencherif M. Convergence of alpha 7 nicotinic acetylcholine receptor-activated pathways for anti-apoptosis and anti-inflammation: central role for JAK2 activation of STAT3 and NF-kappaB. Brain Res 2009;1256:1-7.

7. Gault J, Robinson M, Berger R, Drebing C, Logel J, Hopkins J, et al. Genomic organization and partial duplication of the human alpha7 neuronal nicotinic acetylcholine receptor gene 
(CHRNA7). Genomics 1998;52:173-185.

8. Costantini TW, Dang X, Yurchyshyna MV, Coimbra R, Eliceiri BP, Baird A. A HumanSpecific $\alpha 7-N i c o t i n i c$ Acetylcholine Receptor Gene in Human Leukocytes: Identification, Regulation and the Consequences of CHRFAM7A Expression. Mol Med 2015;21:323-336.

9. Costantini TW, Chan TW, Cohen O, Langness S, Treadwell S, Williams E, et al. Uniquely human CHRFAM7A gene increases the hematopoietic stem cell reservoir in mice and amplifies their inflammatory response. Proc Natl Acad Sci USA 2019;116:7932-7940.

10. Teng P, Liu Y, Dai Y, Zhang H, Liu W-T, Hu J. Nicotine Attenuates Osteoarthritis Pain and Matrix Metalloproteinase-9 Expression via the $\alpha 7$ Nicotinic Acetylcholine Receptor. $J$ Immunol 2019.

11. Liu Y, Wu D, Song F, Zhu C, Hui Y, Zhu Q, et al. Activation of $\alpha 7$ nicotinic acetylcholine receptors prevents monosodium iodoacetate-induced osteoarthritis in rats. Cell Physiol Biochem 2015;35:627-638.

12. Bock K, Plaass C, Coger V, Peck C-T, Reimers K, Stukenborg-Colsman C, et al. What is the effect of nicotinic acetylcholine receptor stimulation on osteoarthritis in a rodent animal model? SAGE Open Med 2016;4:2050312116637529.

13. Orr-Urtreger A, Göldner FM, Saeki M, Lorenzo I, Goldberg L, De Biasi M, et al. Mice deficient in the alpha7 neuronal nicotinic acetylcholine receptor lack alpha-bungarotoxin binding sites and hippocampal fast nicotinic currents. J Neurosci 1997;17:9165-9171.

14. Kamekura S, Hoshi K, Shimoaka T, Chung U, Chikuda H, Yamada T, et al. Osteoarthritis development in novel experimental mouse models induced by knee joint instability. Osteoarthr Cartil 2005;13:632-641.

15. Kadri A, Ea HK, Bazille C, Hannouche D, Lioté F, Cohen-Solal ME. Osteoprotegerin inhibits cartilage degradation through an effect on trabecular bone in murine experimental osteoarthritis. Arthritis Rheum 2008;58:2379-2386.

16. Glasson SS, Chambers MG, Van Den Berg WB, Little CB. The OARSI histopathology initiative - recommendations for histological assessments of osteoarthritis in the mouse. Osteoarthr Cartil 2010;18 Supp1 3:S17-23.

17. Jackson MT, Moradi B, Zaki S, Smith MM, McCracken S, Smith SM, et al. Depletion of protease-activated receptor 2 but not protease-activated receptor 1 may confer protection against osteoarthritis in mice through extracartilaginous mechanisms. Arthritis \& Rheumatology (Hoboken, NJ) 2014;66:3337-3348. 
18. Gosset M, Berenbaum F, Thirion S, Jacques C. Primary culture and phenotyping of murine chondrocytes. Nat Protoc 2008;3:1253-1260.

19. Trellu S, Courties A, Jaisson S, Gorisse L, Gillery P, Kerdine-Römer S, et al. Impairment of glyoxalase-1, an advanced glycation end-product detoxifying enzyme, induced by inflammation in age-related osteoarthritis. Arthritis Res Ther 2019;21:18.

20. Grønlien JH, Håkerud M, Ween H, Thorin-Hagene K, Briggs CA, Gopalakrishnan M, et al. Distinct profiles of alpha7 $\mathrm{nAChR}$ positive allosteric modulation revealed by structurally diverse chemotypes. Mol Pharmacol 2007;72:715-724.

21. Fujii T, Mashimo M, Moriwaki Y, Misawa H, Ono S, Horiguchi K, et al. Physiological functions of the cholinergic system in immune cells. J Pharmacol Sci 2017;134:1-21.

22. Courties A, Sellam J, Berenbaum F. Role of the autonomic nervous system in osteoarthritis. Best Pract Res Clin Rheumatol 2017;31:661-675.

23. Rosas-Ballina M, Olofsson PS, Ochani M, Valdés-Ferrer SI, Levine YA, Reardon C, et al. Acetylcholine-synthesizing $\mathrm{T}$ cells relay neural signals in a vagus nerve circuit. Science 2011;334:98-101.

24. Levine YA, Koopman FA, Faltys M, Caravaca A, Bendele A, Zitnik R, et al. Neurostimulation of the cholinergic anti-inflammatory pathway ameliorates disease in rat collagen-induced arthritis. PLOS ONE 2014;9:e104530.

25. Koopman FA, Chavan SS, Miljko S, Grazio S, Sokolovic S, Schuurman PR, et al. Vagus nerve stimulation inhibits cytokine production and attenuates disease severity in rheumatoid arthritis. Proc Natl Acad Sci USA 2016;113:8284-8289.

26. Schubert J, Beckmann J, Hartmann S, Morhenn H-G, Szalay G, Heiss C, et al. Expression of the non-neuronal cholinergic system in human knee synovial tissue from patients with rheumatoid arthritis and osteoarthritis. Life Sci 2012;91:1048-1052.

27. Grimsholm O, Rantapää-Dahlqvist S, Dalén T, Forsgren S. Unexpected finding of a marked non-neuronal cholinergic system in human knee joint synovial tissue. Neurosci Lett 2008;442:128-133.

28. Beckmann J, Schubert J, Morhenn H-G, Grau V, Schnettler R, Lips KS. Expression of choline and acetylcholine transporters in synovial tissue and cartilage of patients with rheumatoid arthritis and osteoarthritis. Cell and Tissue Research 2015;359:465.

29. Sato T, Abe T, Chida D, Nakamoto N, Hori N, Kokabu S, et al. Functional role of acetylcholine and the expression of cholinergic receptors and components in osteoblasts. FEBS 
Lett 2010;584:817-824.

30. Tucek S. The synthesis of acetylcholine in skeletal muscles of the rat. J Physiol (Lond) 1982;322:53-69.

31. Albuquerque EX, Pereira EFR, Alkondon M, Rogers SW. Mammalian nicotinic acetylcholine receptors: from structure to function. Physiol Rev 2009;89:73-120.

32. Chen D, Patrick JW. The alpha-bungarotoxin-binding nicotinic acetylcholine receptor from rat brain contains only the alpha7 subunit. J Biol Chem 1997;272:24024-24029.

33. Kawakita A, Sato K, Makino H, Ikegami H, Takayama S, Toyama Y, et al. Nicotine acts on growth plate chondrocytes to delay skeletal growth through the alpha7 neuronal nicotinic acetylcholine receptor. PLoS ONE 2008;3:e3945.

34. Shaw S, Bencherif M, Marrero MB. Janus kinase 2, an early target of alpha 7 nicotinic acetylcholine receptor-mediated neuroprotection against Abeta-(1-42) amyloid. J Biol Chem 2002;277:44920-44924.

35. Hajós M, Hurst RS, Hoffmann WE, Krause M, Wall TM, Higdon NR, et al. The selective alpha7 nicotinic acetylcholine receptor agonist PNU-282987 [N-[(3R)-1-Azabicyclo[2.2.2]oct-3yl]-4-chlorobenzamide hydrochloride] enhances GABAergic synaptic activity in brain slices and restores auditory gating deficits in anesthetized rats. J Pharmacol Exp Ther 2005;312:1213-1222.

36. Gullahorn L, Lippiello L, Karpman R. Smoking and osteoarthritis: differential effect of nicotine on human chondrocyte glycosaminoglycan and collagen synthesis. Osteoarthr Cartil 2005;13:942-943.

37. Chan T, Williams E, Cohen O, Eliceiri BP, Baird A, Costantini TW. CHRFAM7A alters binding to the neuronal alpha-7 nicotinic acetylcholine receptor. Neurosci Lett 2019;690:126-131.

38. Baird A, Coimbra R, Dang X, Eliceiri BP, Costantini TW. Up-regulation of the humanspecific CHRFAM7A gene in inflammatory bowel disease. BBA Clin 2016;5:66-71.

39. Kong L, Wang L, Meng F, Cao J, Shen Y. Association between smoking and risk of knee osteoarthritis: a systematic review and meta-analysis. Osteoarthr Cartil 2017;25:809-816.

40. Yin J, Chen W, Yang H, Xue M, Schaaf CP. Chrna7 deficient mice manifest no consistent neuropsychiatric and behavioral phenotypes. Sci Rep 2017;7:39941.

41. Moser N, Mechawar N, Jones I, Gochberg-Sarver A, Orr-Urtreger A, Plomann M, et al. Evaluating the suitability of nicotinic acetylcholine receptor antibodies for standard immunodetection procedures. J Neurochem 2007;102:479-492. 
Figure legends

Figure 1: Non-neuronal cholinergic system expression in murine and human chondrocyte primary cultures and the in vitro effect of nicotine.

A: Representative RT-PCR analysis of the cholinergic system expressed by murine chondrocytes (left) and human OA chondrocytes (right). We used water RNase-free conditions as a negative control for each primer (H20). B: qPCR expression of IL6 (left) and MMP3 (right) by WT murine primary culture of chondrocytes pretreated with 1,10 or $100 \mu \mathrm{M}$ nicotine for 15 minutes and stimulated with $10 \mathrm{ng} / \mathrm{mL}$ IL1 $\beta$ for $24 \mathrm{~h}$ ( $\mathrm{n}=5$ for $\mathrm{WT},{ }^{*} \mathrm{p}<0.05$ using a non-parametric test). The results are normalized to the IL1 $\beta$ condition. C: ELISA results of IL6 (left) and MMP3 (right) in WT murine primary culture of chondrocytes pretreated with 1,10 or $100 \mu \mathrm{M}$ nicotine for 15 minutes and stimulated with $10 \mathrm{ng} / \mathrm{mL}$ IL1 $\beta$ for $24 \mathrm{~h}$ ( $\mathrm{n}=5$ for WT, ${ }^{*} \mathrm{p}<0.05$ using a nonparametric test). The results are normalized to the IL $1 \beta$ condition.

HPRT: hypoxanthine guanine phosphoribosyl transferase; ChAT: choline acetyltransferase; carAT: carnityl acetyltransferase; VAChT: vesicular acetylcholine transporter; AChE: acetylcholine esterase; BChE: butyrylcholine esterase; CHT1: choline transporter-1. IL6: interleukin-6; MMP3: metalloprotease-3, bp : base pair lenght.

\section{Figure 2: Nicotinic acetylcholine receptor expression by murine and human OA chondrocytes}

A: qPCR results of nicotinic acetylcholine receptor (nAChR) subunit expression by murine chondrocytes (left) and human OA chondrocytes (right). B: Representative and semi-quantitative $\alpha$-bungarotoxin binding to $\alpha 7 \mathrm{nAChR}$ on the surface of murine chondrocytes in primary culture. Cells were incubated with biotinylated $\alpha$-bungarotoxin at $20 \mu \mathrm{g} / \mathrm{mL}$ overnight at $4{ }^{\circ} \mathrm{C}$ and analyzed using a streptavidin and DAB protocol and a standard microscope, 20x. The control represents the same experiment without $\alpha$-bungarotoxin incubation. Two independent experiments (one in red and one in green) were performed and each experiment was analysed in 4 different area of 91,000 $\mu \mathrm{m}^{2} \mathrm{C}$ : Representative and semi-quantitative $\alpha$-bungarotoxin-binding $\alpha 7$ nicotinic receptors on the surface of human OA chondrocytes in primary culture. Cells were incubated with biotinylated $\alpha-$ bungarotoxin at $5 \mu \mathrm{g} / \mathrm{mL}$. Two independent experiments (one in red and one in green) were performed and each experiment was analysed in 4 different area of $91,000 \mu \mathrm{m}^{2}$.

This article is protected by copyright. All rights reserved 
Figure 3: Expression of native Chrna7 and the specific duplicate CHRFAM7A by human OA chondrocytes

A: CHRNA7 is the human gene encoding the a7nAChR; it is localized on chromosome 15q13,14 and contains 10 exons. It is assumed that during evolution, a partial duplication of exons 5-10 occurred approximately 1.6 MB upstream on the same chromosome. Thereafter, 4 completely novel exons (A-D) were rearranged in place of the missing exons 1-4 of human a7nAChR, and the 4 new exons of this FAM7 sequence created a new open reading frame to form a new hybrid gene called CHRFAM7A. Surprisingly, the "new" exons (A-D) were derived, in part, from an unrelated sequence, itself originating, in part, from human chromosome 3. Red represents the sequence amplified by the two primers. B: qPCR results of CHRNA7 (native) and CHRFAM7A expression by human OA chondrocytes $(\mathrm{n}=23, * \mathrm{p}<0.05)$. C: Spearman correlation between CHRFAM7A duplicate mRNA expression and basal MMP3 and MMP13 mRNA expression $(n=23, * p<0.05)$. D: MMP3 and MMP13 mRNA expression by human OA chondrocytes compared with CHRFAM7A mRNA expression by human OA chondrocytes $\left(n=23,{ }^{*} p<0.05\right)$.

\section{Figure 4: The nicotine effect is mediated by $\alpha 7 \mathrm{nAch} R$}

A: qPCR expression and B: ELISA production of IL6 (left) and MMP3 (right) by Chrna7-/- murine primary culture of chondrocytes pretreated with 1,10 or $100 \mu \mathrm{M}$ nicotine for 15 minutes and stimulated with $10 \mathrm{ng} / \mathrm{mL}$ IL1 $\beta$ for $24 \mathrm{~h}$ ( $\mathrm{n}=4$ for $\mathrm{qPCR}$ and $\mathrm{n}=5$ for ELISA, ${ }^{*} \mathrm{p}<0.05$ using a nonparametric test). The results are normalized to the IL1 $\beta$ condition. NS: Not significant. C: Calcium influx assay in primary WT and D: Chrna $7^{-/-}$chondrocyte culture. Calcium signaling was investigated by the use of a fluorescent $\mathrm{Ca} 2+$ indicator in murine WT $(n=2)$ and Chrna $7^{-/-}(\mathrm{n}=2)$ chondrocytes treated with buffer alone, Ionomycin $10 \mu \mathrm{M}$ and nicotine $10 \mu \mathrm{M}$. Analyzes were performed using a microscope Olympus IX83 inverted. E: Representative panel of the mean fluorescence measured immediately after buffer alone, Ionomycin $10 \mu \mathrm{M}$ and nicotine $10 \mu \mathrm{M}$ in WT and Chrna $7^{-/-}$chondrocytes. Nicotine did not elicit a transient increase in intracellular calcium. F: qPCR results of IL6, MMP3 and MMP13 expression by human OA chondrocytes stimulated with $10 \mathrm{ng} / \mathrm{mL}$ IL1 $\beta$ with or without a specific a7nAChR agonist, PNU 282987, at $100 \mu \mathrm{M}(\mathrm{n}=3)$.

Figure 5: The lack of Chrna7 is associated with a more severe post-traumatic OA cartilage damage. 
A: $4 \mathrm{X}$ and $10 \mathrm{X}$ representative Safranin $\mathrm{O} /$ fast green-stained sections of the right knee 8 weeks after sham surgery and MNX in WT and Chrna7 ${ }^{-/}$mice. B: Weight of WT $(n=9)$ and Chrna $7^{-/-}$ $(\mathrm{n}=7)$ mice 8 weeks after sham surgery or MNX (not significant between groups). C: OARSI score (0-6, 6 being the worst) D: Synovitis score (0-6, 6 being the worst) and $\mathbf{E}:$ osteophyte score (0-3, 3 being the worst) between WT sham $(n=6)$, Chrna $7^{-/-}$sham $(n=5)$, WT MNX $(n=9)$ and Chrna $7^{-/-}$MNX mice 8 weeks after the sham or MNX surgery $\left({ }^{*} \mathrm{p}<0.05\right)$. 

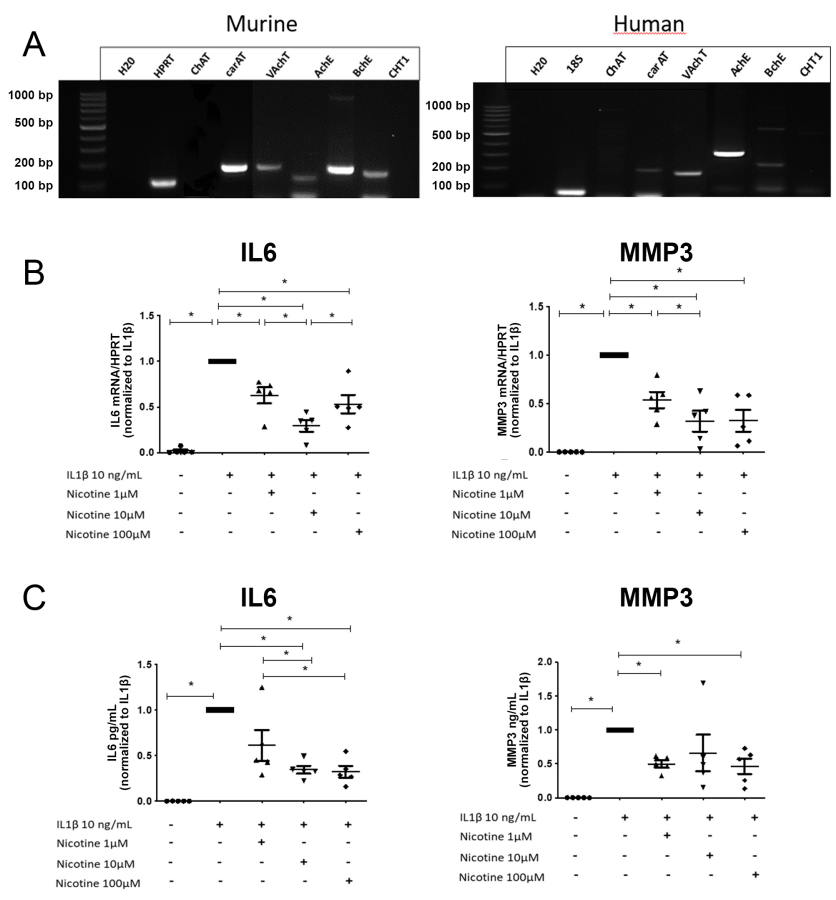

$$
\text { art_41429_f1.tif }
$$



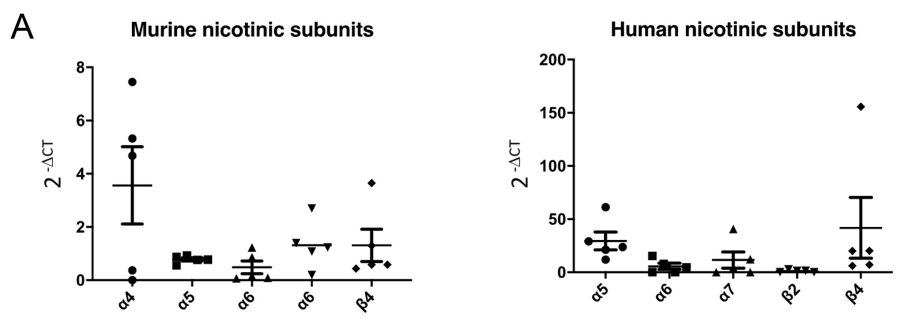

B

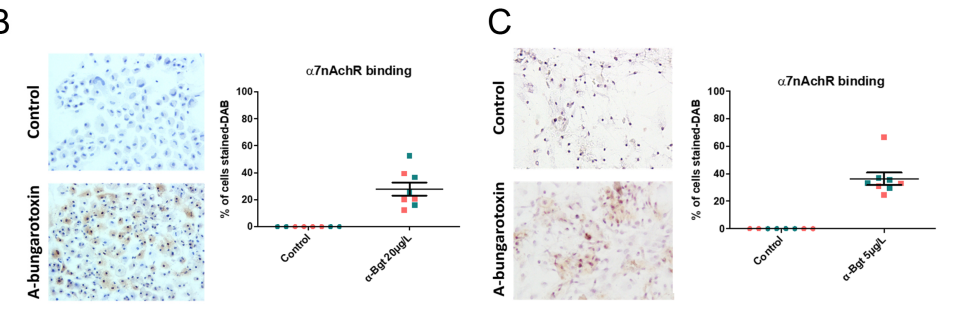

art_41429_f2.tif 


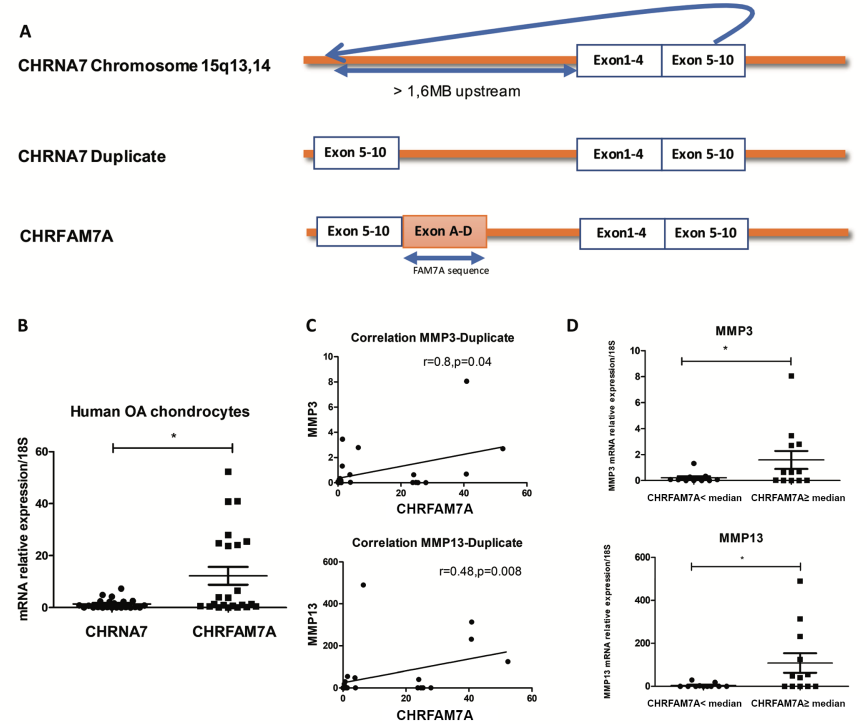

art_41429_f3.tif 

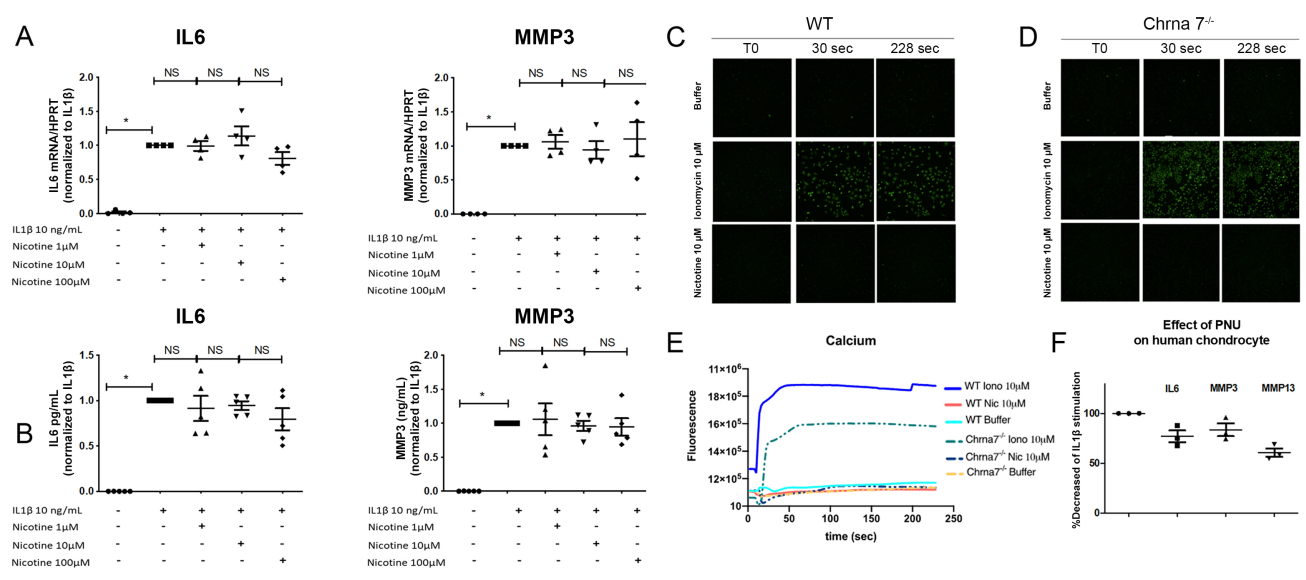

art_41429_f4.tif 

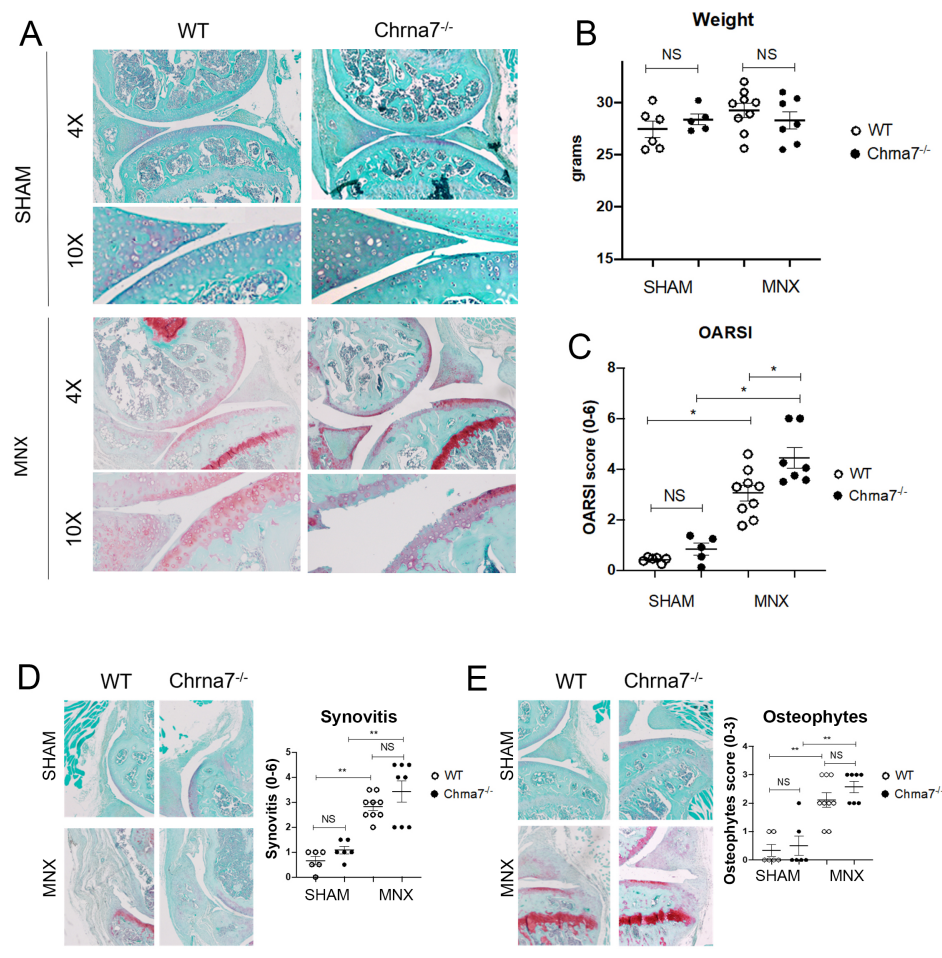

art_41429_f5.tif 